\title{
Rockfall stabilisation of a steep and high slope at West Angelas Mine using pre-tensioned anchored mesh
}

\author{
P.J.G. Lopes Geovert Pty Ltd, Australia
}

T.T. Le Geovert Pty Ltd, Australia

\begin{abstract}
This paper presents a rockfall protection technique employed at the West Angelas iron ore mine located in the Pilbara region of Western Australia. The technique involves the installation of rock bolts and fully dimensioned high tensile wire mesh covering an area of approximately 6,000 $\mathrm{m}^{2}$ of the overhang $150 \mathrm{~m}$ above the pit floor. In order to evaluate the surface stability of the slope and to propose adequate design, an analysis was undertaken using surficial slope stabilisation calculation techniques to define nail geometry, type and diameter and appropriate mesh cover. The final design approach and construction methodology in which rope access technique drilling is required are also discussed and presented in this paper. The design of the rockfall mesh system has been proved to be satisfied as it has successfully stopped an approximately $1.5 \mathrm{~m}^{3}$ detached boulder falling off the crest in February 2012. Due to the simple installation procedure, the high tensile mesh system had allowed the project to be completed in shorter duration with minimal disruptions from technical related issues. Under Geovert's assessment, the high tensile mesh system had saved approximately $\$ 700$ k of cost against other stabilisation options such as rockfall barriers.
\end{abstract}

\section{Introduction}

The West Angelas open pit mine, ore processing plant producing lump and fines ore, stockpiles, reclaimers and train loading facilities is located $110 \mathrm{~km}$ west of Newman in the East Pilbara region of WA.

After a major slip failure along the north wall of the centre pit north in Figure 1, a significant amount of material was left overhanging at the top of the slope producing significant risk of rockfall. Mining of the area directly below the area of overhang was the critical long term operations target for the client. Drill and blast was conducted to reduce the size of the overhang, however it could not be completely removed as some areas suffered damage during the blasting operations. As a consequence, further treatment was required to secure the crest area where residual rockfall hazard were still prevalent. The hazard was identified as a potential surficial instability of the $0.75 \mathrm{~m}$ thick layer of overhanging rock on the slope, a solution was developed and executed with nails and high tensile mesh installed using light weight drilling rigs, cranes and rope access personnel to solve the surficial stability problem.

An active slope stabilisation system retains material in its place with applied forces to prevent material such as unstable rocks and soil masses from sliding or falling. The intention is that no maintenance is required, unlike passive systems such as drapes, bunds or rockfall barriers. The design, layout and bolting of the mesh system considers fast and easy installation, taking into account that most installations are constructed in difficult, steep and remote terrain. Lightweight parts, a minimum of nails and quick mesh installation are important construction aspects. The wire mesh, rock bolts and the bespoke spike plates are the major components of the system. Loads arising from sliding rocks and soil masses are transmitted to spike plate and nails. Diamond shaped wire meshes, made out of high tensile steel wires have proven to be very effective in their bearing capacity. The mesh is fabricated with $\mathrm{Al} / \mathrm{Zn}$ coated wires to improve the corrosion protection for a long lifetime.

The principal function of the nailing and the spike plates is to retain the mesh. Special diamond-shaped system spike plates matching the high tensile mesh serve to fix it to soil or rock nails. By tightly 
pre-tensioning the spike plates on the nail head into the ground to be stabilised, the mesh is uniformly tensioned to the face transferring force into the surface and tightening the spaces between the nails. Rock bolts transmit the forces into the substrate. The appropriate nail pattern is determined by applying the (Geobrugg, 2010) dimensioning concept, considering both geotechnical as well as material aspects.

\section{$2 \quad$ Available data}

The ore exploration takes place in the Hamersley Iron Province. The province is characterised by a 2500 million years old late Archaean and early Proterozoic rock formation known as Hamersley Group, predominantly composed of Banded Iron Formation (BIF) which is formed by alternate layers of iron-rich and silica-rich layers. The Marra Mamba Iron Formation hosts the principal orebody. The slip occurred by planar sliding on a shale bed dipping into the pit at an angle of approximately 40 degrees. The dimensions of the slip failure at the slip are shown in Figure 2.

No significant hydrological influence has been identified by onsite visual inspection. Due to the conditions of the post failure back scarp, rock fall events could be trigged by increase in ground accelerations caused by blasting, earthquakes, heavy trucks and drillings. Boulders may start to move and finally fall down the slope.

The geotechnical parameters used in the design were based on prior site experience:

- Inter-ramp slope angle $\alpha=40^{\circ}$.

- Slab thickness (overhang thickness) $\mathrm{t}=0.75 \mathrm{~m}$.

- Sliding interface shear strength $c^{\prime}=0 \mathrm{kPa}$, friction $\varphi^{\prime}=320$.

- Specific weight of the rock was assumed to be $30 \mathrm{kN} / \mathrm{m}^{3}$. 


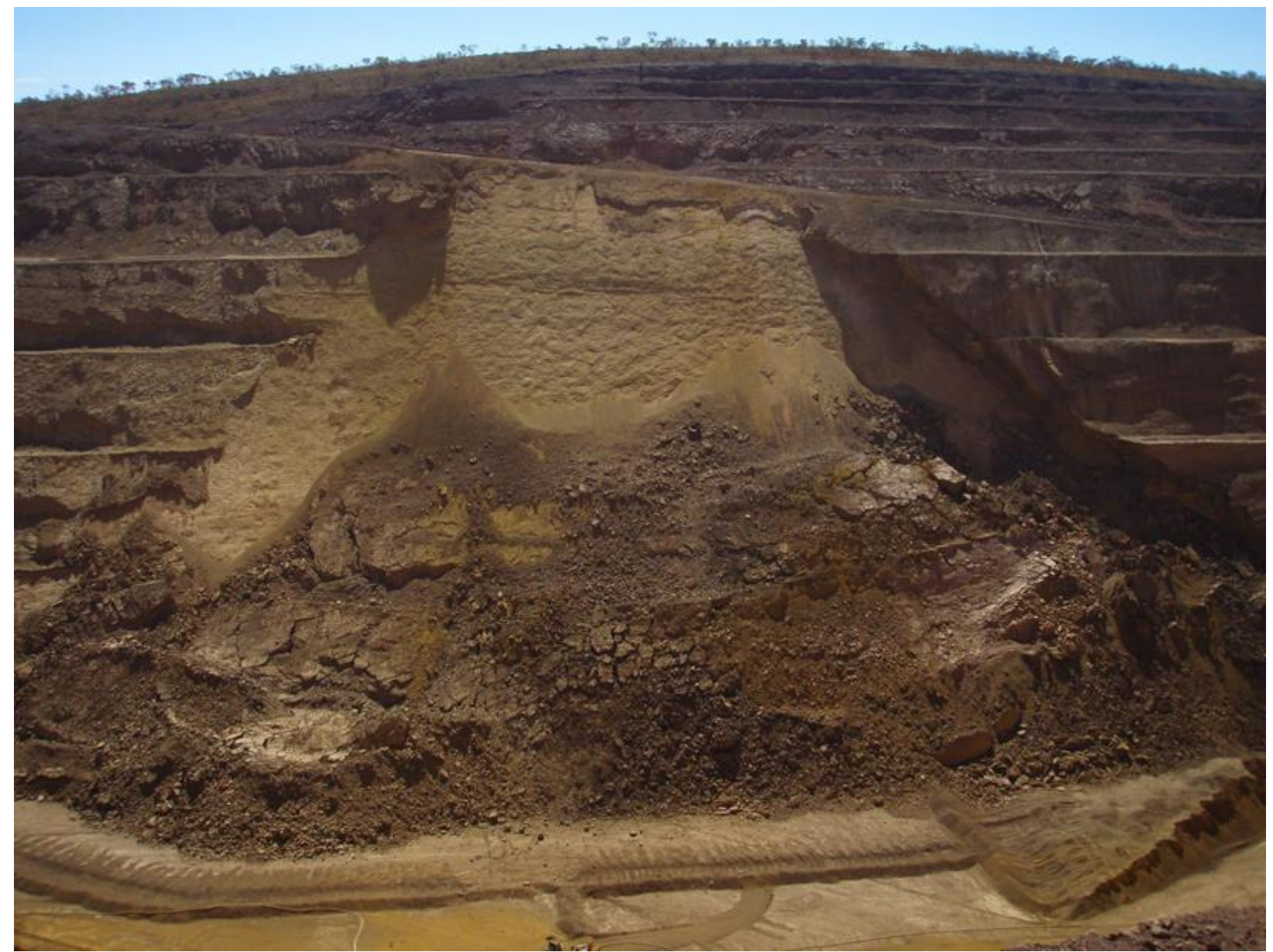

Figure 1 Major slip failure at north wall, West Angelas

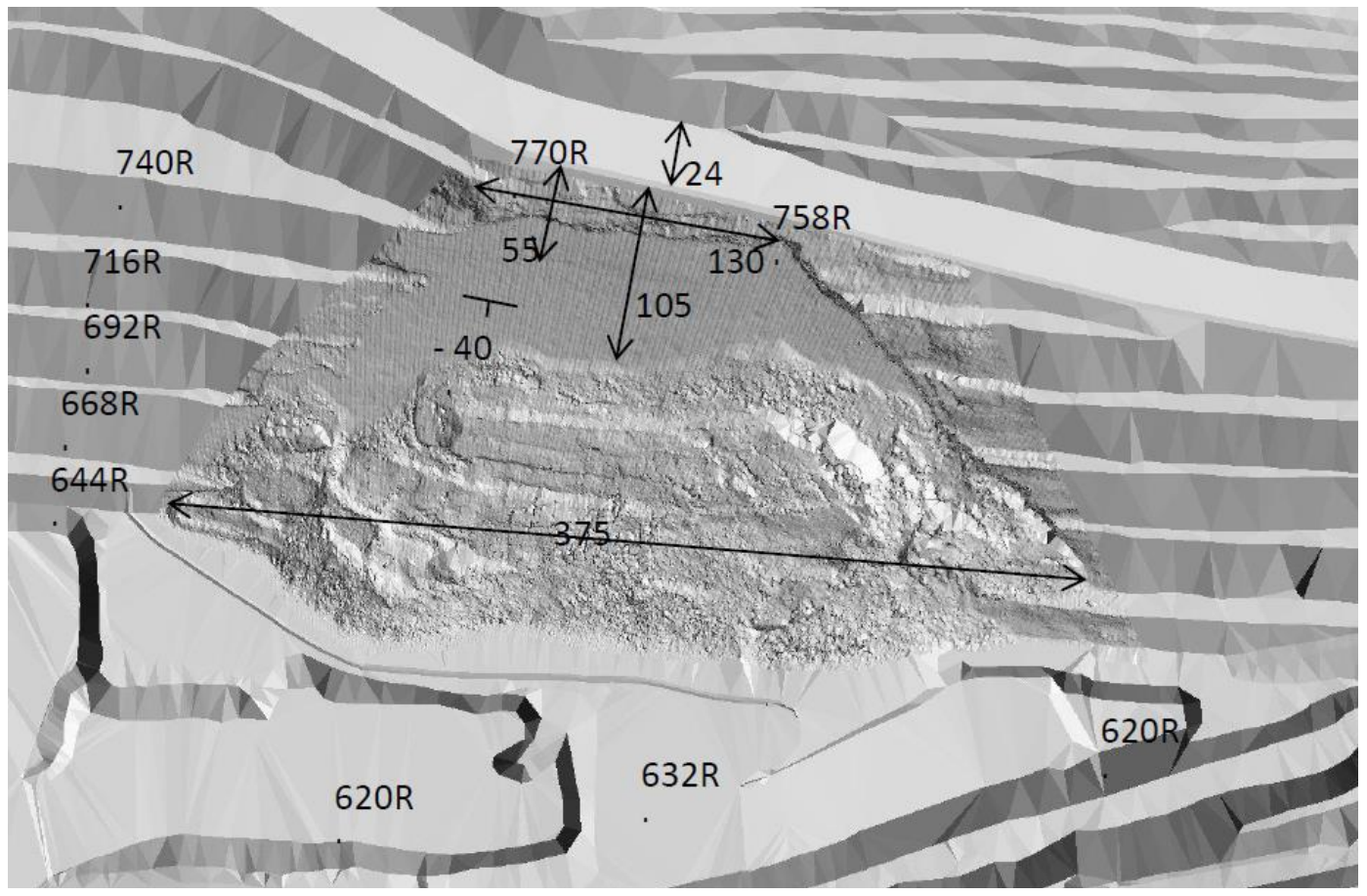

Figure 2 Dimensions of slope area (m and degrees), West Angelas 


\section{Rockfall stabilisation design}

\subsection{Design constraints}

The selected recovery option required for the bulk of the slip to be mined out, to allow the high grade ore directly below the slip area be accessed (Joass, 2013). Due to the drill and blast operation to remove or reduce the overhanging risk, work has been focused on securing the crest area which has suffered some damage during the blasting operations. Cracking over time, as a result of weathering and/or effects of stress relief, may start to break up further blocks and potentially unravel and reform further overhang.

The rockfall risk at the top of the plane failure, at 740 to $770 \mathrm{RL}$, approximately $4,000 \mathrm{~m}^{2}$ as shown in Figure 2, presented significant safety challenge for ongoing mining activities and a construction methodology for rockfall protection. With these difficulties, mitigation options were limited to those which should be completed using top-down installation techniques. This therefore eliminated the option of barrier construction directly at the middle batter of the high wall without prior stabilisation to provide safe access for construction crews. The stabilisation design was therefore based on pinning and supporting the crest overhang. In this case the Geobrugg TECCO mesh (Geobrugg, 2010) was selected due to its strength properties, flexibility, and considering also the execution time and costs related to other solutions.

Normal mine operations of blasting and heavy machine operation, combined with the potential of heavy rainfall in the area, could work to loosen materials damaged during blasting and increase the likelihood of rockfall occurring in the future. The slope stabilisation system was expected to work as a flexible facing to stabilise and prevent these surficial blocks from falling from the slope and help to maintain the crest area.

\subsection{Design analysis and calculation}

Rio Tinto geotechnical engineers provided geotechnical design recommendations and risk management plans for the ore recovery. Global slope stability was therefore not part of the design-and-construct project for rockfall mitigation to allow safe mining to be undertaken below. It was acknowledged the existence of two potential slip surfaces (approximately $30-40 \mathrm{~cm}$ thick shale bed) separated by about $2 \mathrm{~m}$. It was initially unclear whether the failure had occurred on the upper, or the lower shale bed, however subsequent investigations indicated that the failure was caused by the upper shale bed (Joass, 2013). Hence, only the surficial layer down to a depth of $0.75 \mathrm{~m}$ was defined and considered in the analysis for the surficial stability treatment.

In order to evaluate the surface stability of the slope and to propose adequate measures, an analysis based on the software for surficial slope stabilisation design developed by Geobrugg (2010), has been carried out on a characteristic cross-section. The results of the analysis provide information such as nail spacing, type/diameter and appropriate mesh cover. See input parameters on Table 1.

Table 1 Design input

\begin{tabular}{lccc}
\hline Description & Symbol & Value & Unit \\
\hline Slope inclination & $\alpha$ & 40 & degrees \\
Nail distance horizontal & $\mathrm{a}$ & 3 & $\mathrm{~m}$ \\
Nail distance in line of slope & $\mathrm{b}$ & 3 & $\mathrm{~m}$ \\
Layer thickness & $\mathrm{t}$ & 0.75 & $\mathrm{~m}$ \\
Radius of pressure cone, top & $\zeta$ & 0.15 & $\mathrm{~m}$ \\
Inclination of pressure cone to horizontal & $\delta$ & 45 & degrees \\
Friction angle ground (characteristic value) & $\phi$ & 32 & degrees \\
Cohesion ground (characteristic value) & $\mathrm{ck}$ & 0 & $\mathrm{kPa}$
\end{tabular}


Volume weight ground (characteristic value)

Slope-parallel force

Pre-tensioning force of the system

Nail inclination to horizontal

Partial safety correction value for friction angle

Partial safety correction value for cohesion

Partial safety correction value for volume weight

Model uncertainty correction value

Elements of the system - as specified by the manufacturers

Applied mesh type

Applied spike plate

Bearing resistance of mesh to selective, slope-parallel tensile stress

Bearing resistance of mesh to pressure stress in nail direction

Bearing resistance of the mesh against shearing-off in nail direction

Applied nail type

Corrosion allowance

Bearing resistance of nail to tensile stress

Bearing resistance of nail to shear stress

Cross-section area of the applied nail with rusting away

$\begin{array}{ccc}\gamma_{\mathrm{k}} & 30 & \mathrm{kN} / \mathrm{m}^{3} \\ Z_{\mathrm{d}} & 15 & \mathrm{kN} \\ V & 30 & \mathrm{kN} \\ \psi & 20 & \text { degrees } \\ \gamma_{\phi} & 1 & \\ \gamma_{c} & 1 & \\ \gamma_{Y} & 1 & \\ \gamma_{\text {mod }} & 1.5 & \end{array}$

TECCO G65/3 mm

TECCO system spike plate

$\begin{array}{cc}Z_{R}(k N) & 30 \\ D_{R}(k N) & 180 \\ P_{R}(k N) & 90\end{array}$

GEWI D=25 mm

Included

$T_{\text {Rred }}(k N)$

173

$\mathrm{S}_{\text {Rred }}(\mathrm{kN})$

100

$A_{\text {red }}\left(\mathrm{mm}^{2}\right)$

346

\subsubsection{Investigation of surficial slope-parallel instabilities}

The investigation of surficial slope-parallel instabilities concerns with possibility of the cover layers sliding off the stable subsoil. In this case, the nailing system is the stabilising agent against the slide hence the bearing capacity of the nails against the sliding effect is required to be investigated. Figure 3 demonstrates the relevant forces acting on the nailing system.

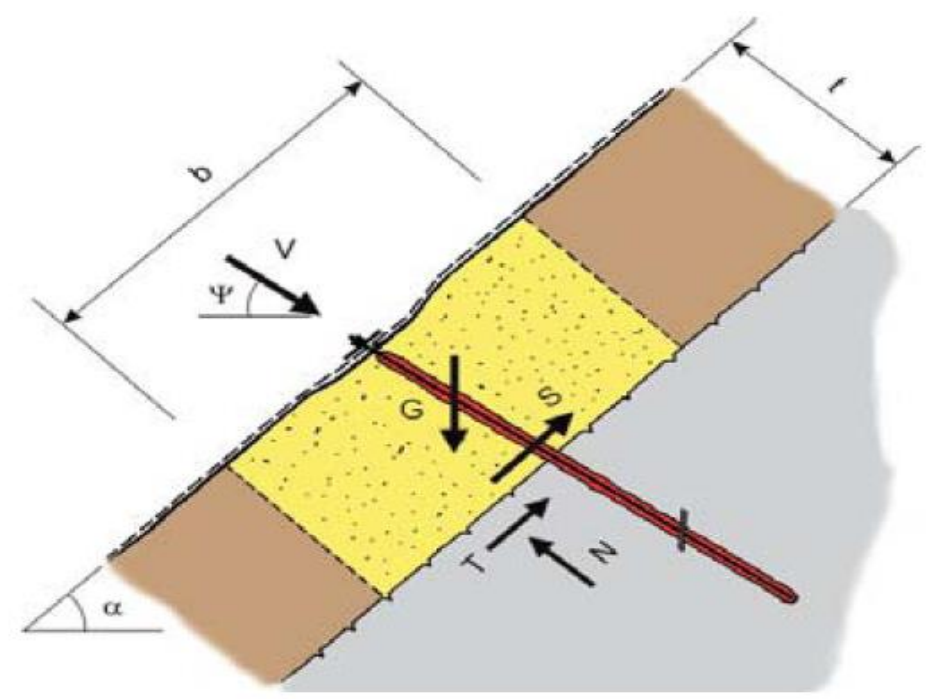

Figure 3 Forces acting on the supported block (Geobrugg, 2010) 
Where:

G: dead load of the cubic body (highlighted in yellow)

$\mathrm{T}$ and $\mathrm{N}$ : the reaction in vertical and tangential direction of the sliding surface

$S$ : shear stress acting on the nail

$\mathrm{t}$ : thickness of the layer

$b$ : nail distance in line of the slope

$\mathrm{V}$ : Pre-tensioning force of the system

$\alpha$ : slope inclination

$\psi$ : nail inclination to the horizontal

According to Eurocode 7 (CEN/TC 250, 1997) the following three proofs of bearing safety must be established in the context of the investigation of surficial slope-parallel instabilities.

- Proof against a surficial layer sliding off.

- Proof of the mesh against puncturing.

- Proof of the resistance of the nail to combined stress.

\subsubsection{Proof against sliding off of a surficial layer parallel to the slope}

This is to prove that the cubic body of width $a$, length $b$ and thickness $t$ does not slide off the sliding surface which is inclined by the angle $\alpha$ in respect to the horizontal plane.

The governing condition is

$$
S_{d} \leq \frac{S_{R}}{\gamma_{S R}}
$$

$S_{d} \quad=$ dimensioning value of the shear stress under consideration of the dimension values of the geotechnical parameters and of the external, stabilising force $\mathrm{V}_{\mathrm{d} 1}$ at dimensional level,

Whereby the following applies:

$$
V_{d 1}=V * \gamma_{d 1}\left(\gamma_{d 1}=0.8 \text { is generally taken }\right) .
$$


$S_{d}$ is calculated as below:

$$
\begin{gathered}
S_{d}=\frac{1}{\gamma_{\text {mod }}}\left\{\gamma_{\text {mod }} * G * \sin \alpha-V_{d 1} * \gamma_{\text {mod }} * \cos (\psi+\alpha)-c^{\prime} * A-\left[G * \cos \alpha+V_{d 1} * \sin (\psi+\alpha)\right] * \tan \phi\right\}(3) \\
G=\gamma_{\mathrm{k}} * \mathrm{a} * \mathrm{~b} * \mathrm{t}=30 * 3 * 3 * 0.75=202.5 \mathrm{kN} \\
V_{d 1}=V * \gamma_{d 1}=30 * 0.8=24 \mathrm{kN}
\end{gathered}
$$

Therefore, the value of $S_{d}=44.9 \mathrm{kN} \leq \frac{S_{R}}{\gamma_{S R}}=\frac{100}{1.5}=66.67 \mathrm{kN}$ (fulfilled).

\subsubsection{Proof of mesh against puncturing}

This proof is to verify if the mesh is able to absorb the force $V$ applied in nail direction and transfer it into the stable subsoil. Hereby, the value of the externally applied force $V$ is compared with the bearing resistance of the mesh to pressure stress in nail direction, whereby the resistance correction value for puncturing is taken into account:

$$
V_{d 2} \leq D_{R} / \gamma_{D R}
$$

$V_{d 2}$ is the dimensioning value of the external force $\mathrm{V}$ with which the slope stabilisation system is pre-tensioned against the nails $V_{d 2}=V * \gamma_{V 2}$ where $\gamma_{V 2}$ is 1.5 as generally taken.

$$
\text { So, } V_{d 2}=30 * 1.5=45 k N \leq \frac{180}{1.5}=120 k N \text { (fulfilled) }
$$

\subsubsection{Proof of resistance of the nail to combined stress}

This proof is to verify the capacity of the nail under simultaneous applied tensile stress from the pre-tensioning and the shear stress from the potential sliding body. The governing condition is:

$$
\sqrt{\left\{\frac{V_{d 2}}{T_{R} / \gamma_{V R}}\right\}^{2}+\left\{\frac{S_{d}}{S_{R} / \gamma_{S R}}\right\}^{2}}=\sqrt{\left\{\frac{45}{173 / 1.5}\right\}^{2}+\left\{\frac{44.9}{100 / 1.5}\right\}^{2}}=0.778 \leq 1 \text { (fulfilled) }
$$

\subsubsection{Investigation of local instabilities between the individual nails}

The second investigation focuses at the local bodies liable to break out between the individual nails. This investigation is in order to ensure that all local bodies liable to break out will be retained within the mesh and maximum occurring forces are absorbed and transferred to the stable substrate. In a triangular nail pattern, above each nail is a field of width and length $2 \times b$ which must be secured against local stabilities (Figure 4).

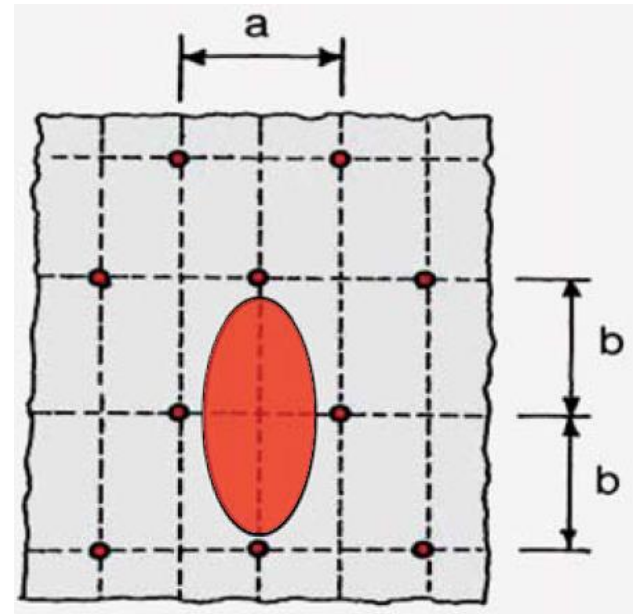

\section{Figure 4 General nail arrangement (Geobrugg, 2010)}

As every single nail is pre-tensioned to a certain load ( $30 \mathrm{kN}$ in this case) by tightening its nut, this will cause the spike plate (Figure 5) to press firmly into the ground. As part of the analysis, the pressure cone region is 
not considered as part of the local body liable to slide off. The pressure cone is characterised by the radius of the pressure cone (usually $0.5 *$ width of spike plate $=0.5 * 0.3=0.15 \mathrm{~m}$ ) and the inclination angle $\delta$ $\left(45^{\circ}\right)$. Hence, the local body's cross-section area is trapezoidal as seen in Figure 5. The trapezoidal cross-section can be transformed to rectangular with an equivalent area of width.

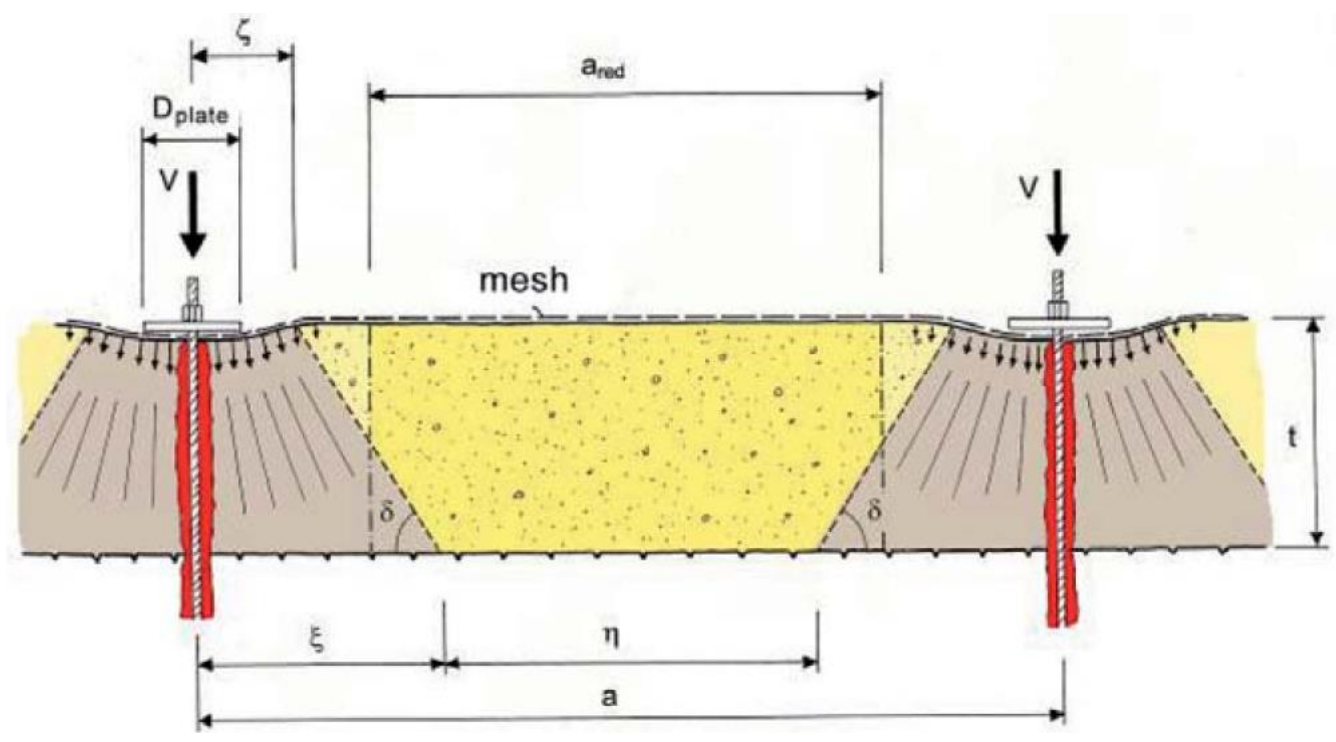

Figure 5 Cross section of the local body liable to slide off with the nail's pressure cone (Geobrugg, 2010)

Where:

Dplate: diameter of the base plate

$\eta:$ is the distance between the base of the pressure cone of two adjacent nails

$\mathrm{V}$ : pre-tensioning force of the system

$\zeta$ : radius of the top of the pressure cone

$\xi$ : radius of the base of the pressure cone

$\delta$ : inclined angle of the pressure cone $=45^{\circ}$

$$
a_{\text {red }}=\left(a-\frac{t}{\tan \delta}-2 * \zeta\right)=1.95 m
$$

Depend on the slip failure angle $\beta$, there are 2 fault mechanisms of single-body sliding: mechanism $A$ and double-body sliding mechanism $B$ (Figure 6).
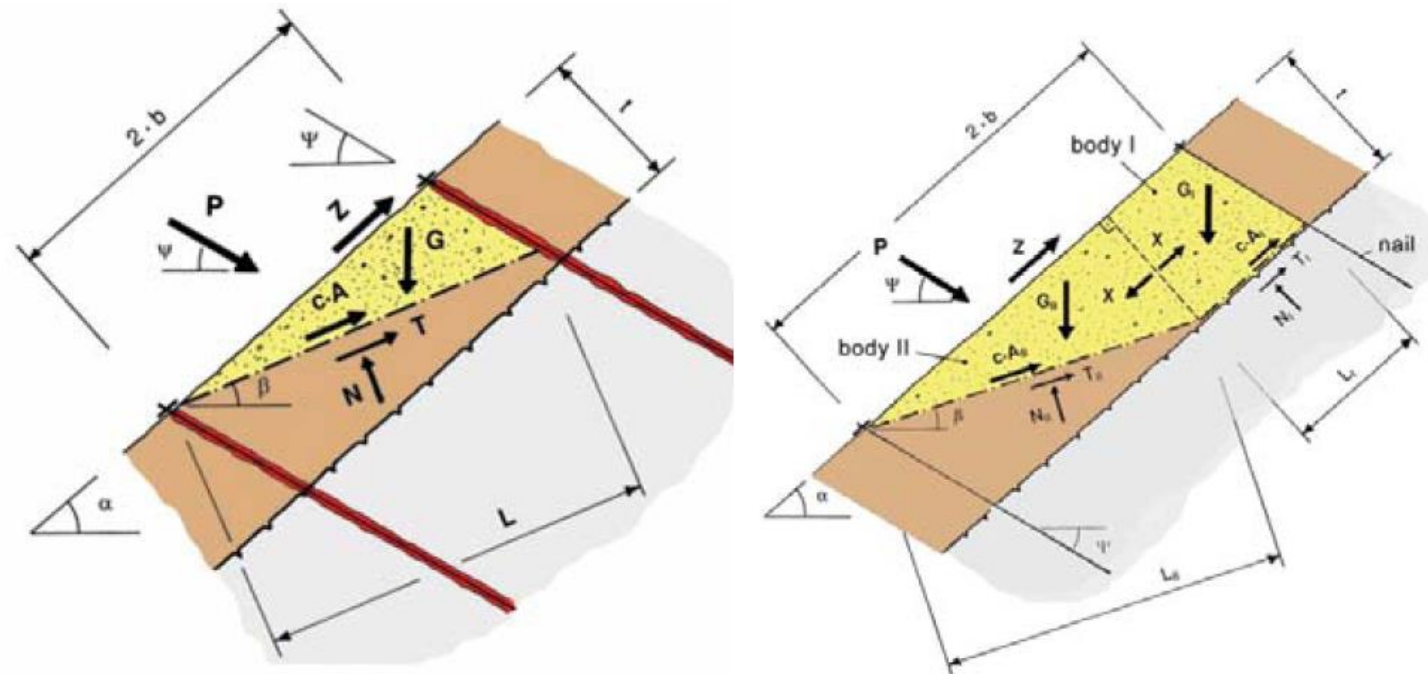

Figure 6 Fault mechanism A and fault mechanism B (Geobrugg, 2010)

Where:

$\mathrm{P}:$ Max stress on the mesh for shearing-off nail direction 
c.A: is the surface area of the sliding body and the cohesion of the ground. This measures the shear resistance Z: Slope parallel force

As can be observed, the value for $\beta$ ranges from -20 to $40^{\circ}$ in relation to the horizontal. The range of $\beta$ in which each mechanism occurs is as:

- Mechanism A: $33.35^{\circ} \leq \beta \leq 40^{\circ}$.

- Mechanism B: $-20^{\circ} \leq \beta \leq 33.35^{\circ}$.

By equilibrium the force $P$ is determined in the two fault mechanism as follows (Geobrugg, 2010):

Fault mechanism A:

$$
P[k N]=\frac{G\left[\gamma_{\bmod } * \sin \beta-\cos \beta * \tan \phi^{\prime}\right]-Z *\left[\gamma_{\bmod } * \cos (\alpha-\beta)-\sin (\alpha-\beta) * \tan \phi^{\prime}\right]-c^{\prime} A}{\gamma_{\bmod } * \cos (\beta+\psi)+\sin (\beta+\psi) * \tan \phi^{\prime}}
$$

Where $\gamma_{\text {mod }}=1.5, \mathrm{~A}=\mathrm{L}^{*} a_{\text {red }}$ and $\mathrm{G}$ is the dead weight of the body liable to break out and is calculated in term of $\beta$ as below:

$$
G=\gamma_{k} * a_{r e d} * \frac{4 b^{2} * \sin (\psi+\alpha) * \sin (\alpha-\beta)}{2 * \sin (\beta+\psi)}
$$

Fault mechanism B: Fault mechanism B is characterised by two bodies liable to break out: the upper trapezoidal body presses over the contact force $X$ onto the lower wedge-shaped body II. The width of the two bodies is $a_{\text {red }}$. The force $\mathrm{X}$ is calculated as below:

$$
\begin{aligned}
& X[k N]=\frac{1}{\gamma_{\text {mod }}} *\left\{G_{I} *\left(\gamma_{\text {mod }} * \sin \alpha-\cos \alpha * \tan \phi^{\prime}\right)-c^{\prime} * A_{I}\right\} \\
& P(k N)=\frac{G_{I I}\left[\gamma_{\bmod } * \sin \beta-\cos \beta * \tan \phi^{\prime}\right]+(X-Z) *\left[\gamma_{\bmod } * \cos (\alpha-\beta)-\sin (\alpha-\beta) * \tan \phi^{\prime}\right]-c^{\prime} A_{I I}}{\gamma_{\bmod } * \cos (\beta+\psi)+\sin (\beta+\psi) * \tan \phi^{\prime}}
\end{aligned}
$$

Where:

$$
\begin{gathered}
G_{I}=\gamma_{k} * a_{r e d} * t * \frac{1}{2} *\left[4 b-t *\left(\frac{1}{\tan (\alpha-\beta)}+\frac{\sin (\psi+\beta)}{\sin (\alpha-\beta)+* \sin (\psi+\alpha)}\right)\right] \\
G_{I I}=\gamma_{k} * a_{r e d} * \frac{t^{2}}{2 \tan (\alpha-\beta)}
\end{gathered}
$$

\subsubsection{Proof of the mesh against shearing off at the upslope edge of the spike plate}

If the design supported block is able to break out and therefore to slide off, it presses outwards in the area of lower nail with a maximum force $P$ which is determined using the maximum value of either fault mechanism A or fault mechanism B. The mesh must be sufficiently strong to withstand this shear stress and to carry the force $P$ away over the spike plate onto the nail. That means the condition below must be true:

$$
P_{d} \leq \frac{P_{R}}{\gamma_{P R}}
$$

$P_{d}$ is dimensioning value of the maximum shear stress on the mesh at the upslope edge of the spike plate on the lower nail.

$P_{R}$ is bearing resistance of the mesh against shearing off in nail direction, and to be determined by means of test developed specifically for the purpose. $P_{R}=90 \mathrm{kN}$.

$\gamma_{P R}$ is resistance correction value and is generally taken as 1.5 .

By utilising the set of equations provided in the above section, the value of maximum force $P$ in each fault mechanism is calculated and the greater value between fault mechanism $A$ and fault mechanism $B$ is the value for $P_{d}$.

- For mechanism A, $P_{\max }=8.83 \mathrm{kN}$ at $\beta=33.35^{\circ}$.

- For mechanism $B, P_{\max }=32.0 \mathrm{kN}$ at $\beta=22.2^{\circ}$. 
Therefore, $P_{d}=32.0 \mathrm{kN} \leq \frac{P_{R}}{\gamma_{P R}}=\frac{90}{1.5}=60 \mathrm{kN}$ (fulfilled).

\subsubsection{Proof of the mesh to selective transmission of the slope parallel force $Z$ onto the upper nail}

The slope parallel force $Z$ must be transmitted selectively from the mesh over the spike plate onto the upper nail. Proof of bearing safety concerning the selective transmission of the force $Z$ from the mesh onto the upper nail is established as:

$$
Z_{d} \leq Z_{R} / \gamma_{Z R}
$$

$Z_{d}$ is the dimensioning value of the stress in slope-parallel direction.

$Z_{R}$ is bearing resistance of the mesh against selective, slope-parallel tensile stress.

$Z_{P R}$ is resistance correction value and is generally taken as 1.5 .

So, $Z_{d}=15 k N \leq \frac{30}{1.5}=20$ (fulfilled).

\subsection{Proposed design and solution}

According to the RUVOLUM (Geobrugg, 2013) concept calculation provided previously, all the design requirements are fulfilled. The distance between single nails can be optimised to a maximum distance of $3.0 \times 3.0 \mathrm{~m}$. Furthermore $25 \mathrm{~mm}$ Hot Dipped-Galvanised HDG All-Thread Bar Gr500 was proposed to be used in the nailing system.

Hence, generally the $25 \mathrm{~mm}$ HDG All-Thread Bar Gr500 Nails $-\mathrm{L}=3.5 \mathrm{~m}$ in $65 \mathrm{~mm}$ diameter grouted hole would be located $3 \times 3 \mathrm{~m}$ spacing from centre to centre.

According to the geotechnical unit exposed on the slope face, shale in this case, theoretically the bond strength between rock/grout ranges between 205 and $550 \mathrm{kPa}$ (Tom Armour, 2000). The nail length of $3.5 \mathrm{~m}$ in $65 \mathrm{~mm}$ diameter grouted hole is assumed to be more than sufficient to fulfil the pre-tension load requirement ( $30 \mathrm{kN}$ in this case).

At the top row, the Nails length would be extended to $L=5.5 \mathrm{~m}$ with $3 \times 3 \mathrm{~m}$ spacing to provide additional resistance to potential loosening caused by blasting.

At the slope head it was proposed to use additional shorter spaced nails - $25 \mathrm{~mm}$ Hot Dipped Galvanised All-Thread Bar Gr500, length $3.5 \mathrm{~m}$, spacing $2.80 \mathrm{~m}$ to stabilise the slope crest. The TECCO mesh should additionally be fixed to a wire rope at the crest of the slope. A typical design drawing of this project is illustrated schematically in Figure 7.

As the local rock conditions may deviate from the assumptions herein and/or if global instability of the slope needs to be addressed, the nail pattern may need to be reduced and nail lengths increased according to checks made during construction.

TECCO mesh G65 has a longitudinal strength of $150 \mathrm{kN} / \mathrm{m}$ and a lateral strength of $60 \mathrm{kN} / \mathrm{m}$.

The mesh has a uniform strength with no weak points at the seam of the panels. If a wire breaks, the spiral does not unravel. 


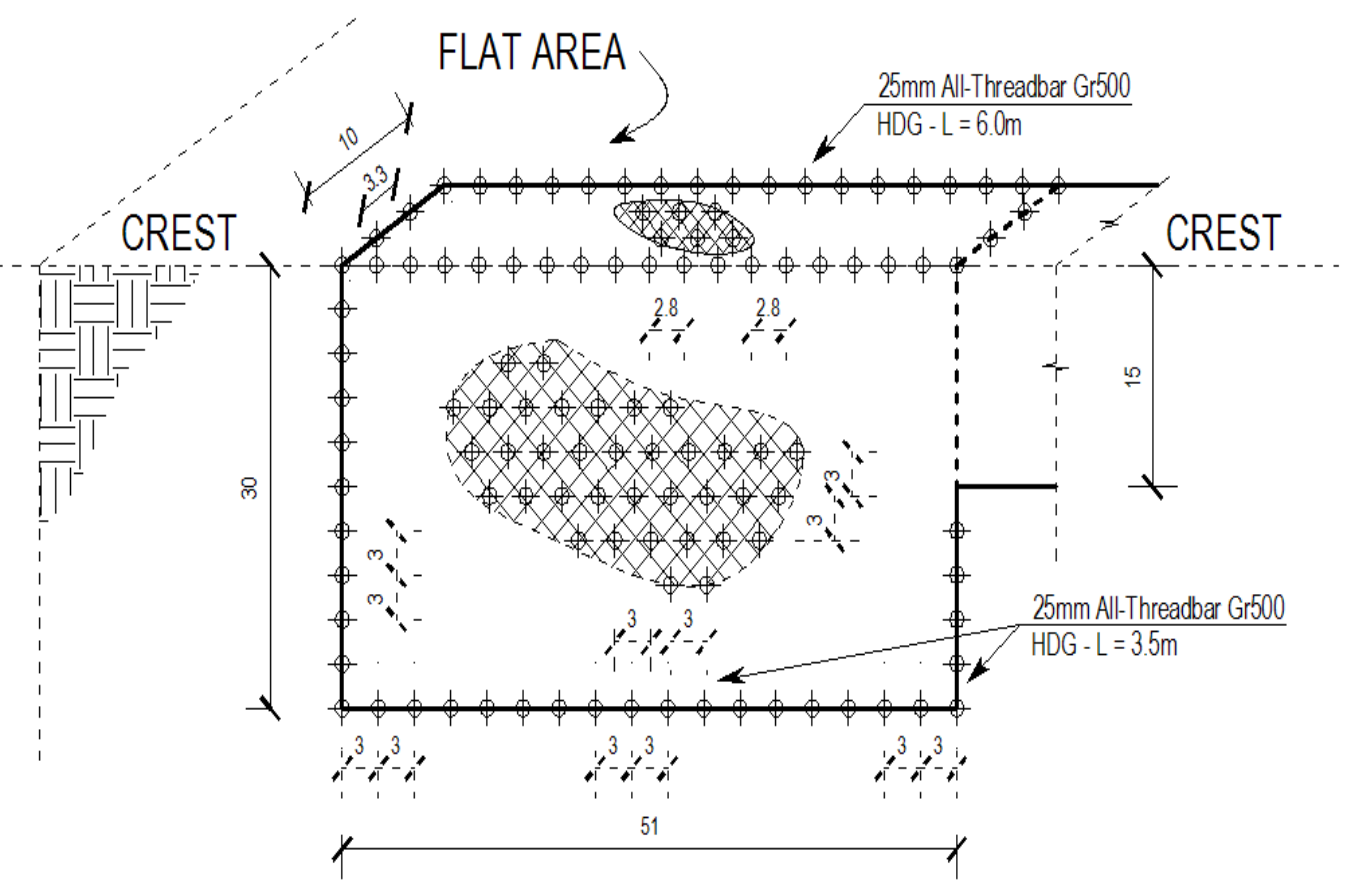

Figure 7 Schematic arrangements of rock anchor and TECCO mesh

\section{$4 \quad$ Project execution and results}

A total of 498 anchor locations were drilled. In addition, 4 locations were drilled in order to install the wire rope anchors. As part of the design, locations were drilled to a minimum depth of $3.5 \mathrm{~m}$ utilising light weight drill rigs specially developed for this type of work (Figure 8). Following drilling, a $4 \mathrm{~m} \times 25 \mathrm{~mm} \varnothing$ galvanised thread bar was installed and prepared for grouting.

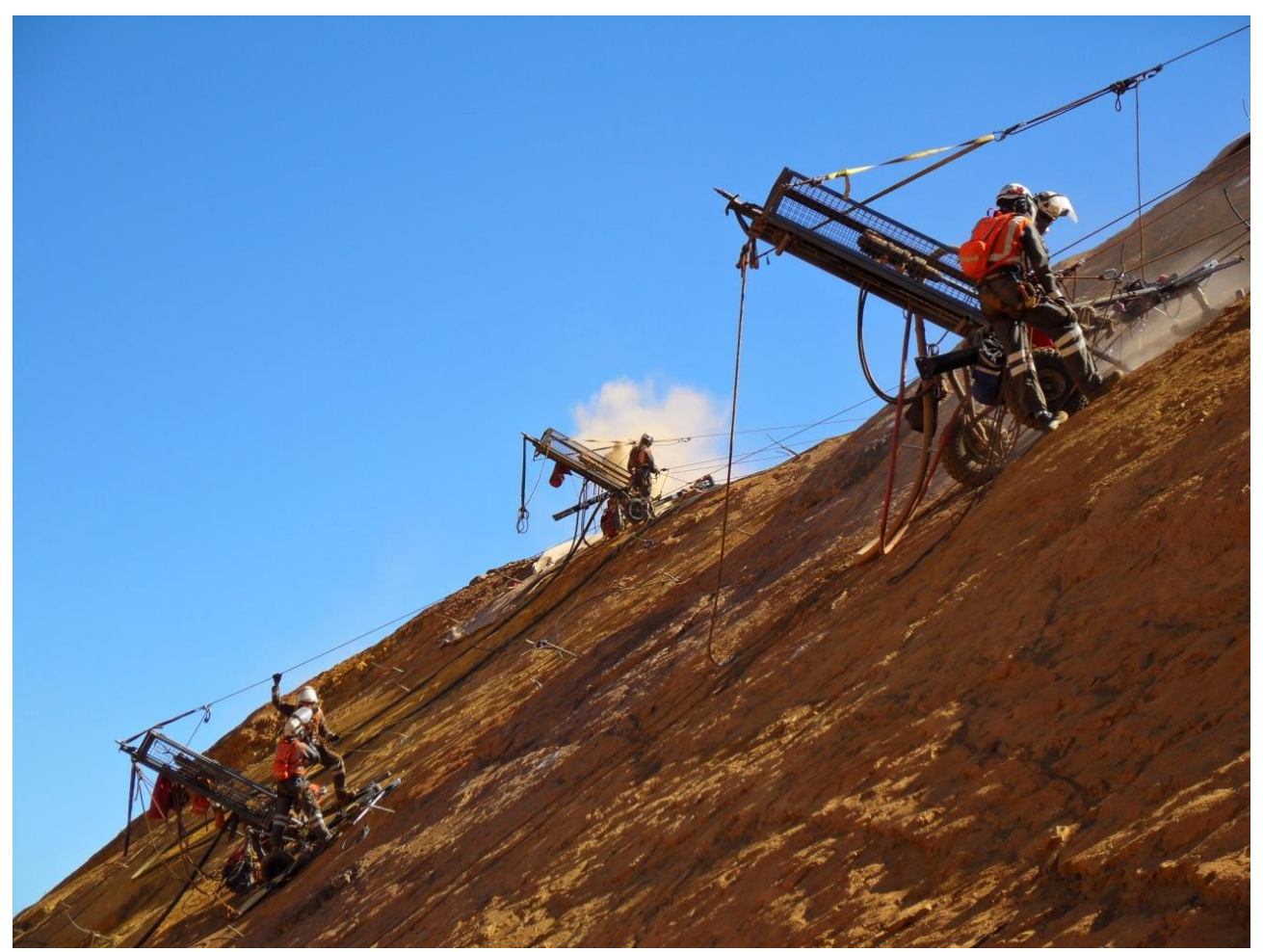

Figure 8 Rope-access drilling with light weight drill rigs at $\mathbf{1 5 0} \mathrm{m}$ above the pit base 
Representative grout samples were collected (grout cubes) and tested at a NATA accredited laboratory, to demonstrate compliance with the specified compressive strength ( $\mathrm{MPa}$ ).

Following the installation of the anchor bars, approximately $5 \%$ of the total number of installation was tested to $120 \%$ of the design load for acceptance utilising a hydraulic jack.

Anchors were selected at random for testing across the full extent of the project. Further, a number of anchors were specifically selected and tested in an observed area of poor ground condition encountered and notified by drillers and through review of associated drill logs.

Succeeding the mesh lay out, the mesh was stitched together and spike plates and nuts were positioned and tensioned in place on each of the anchor points. Finally the perimeter cable was installed.

During construction, TDR cables were also installed up to $100 \mathrm{~m}$ down the slope to depths of $20 \mathrm{~m}$ to allow for continued monitoring of the slope.

Since construction, ongoing mining operations occurring in proximity to the slope have caused several boulders to be released and fell from the overhang (Figure 9), which were retained by the installed protection system.

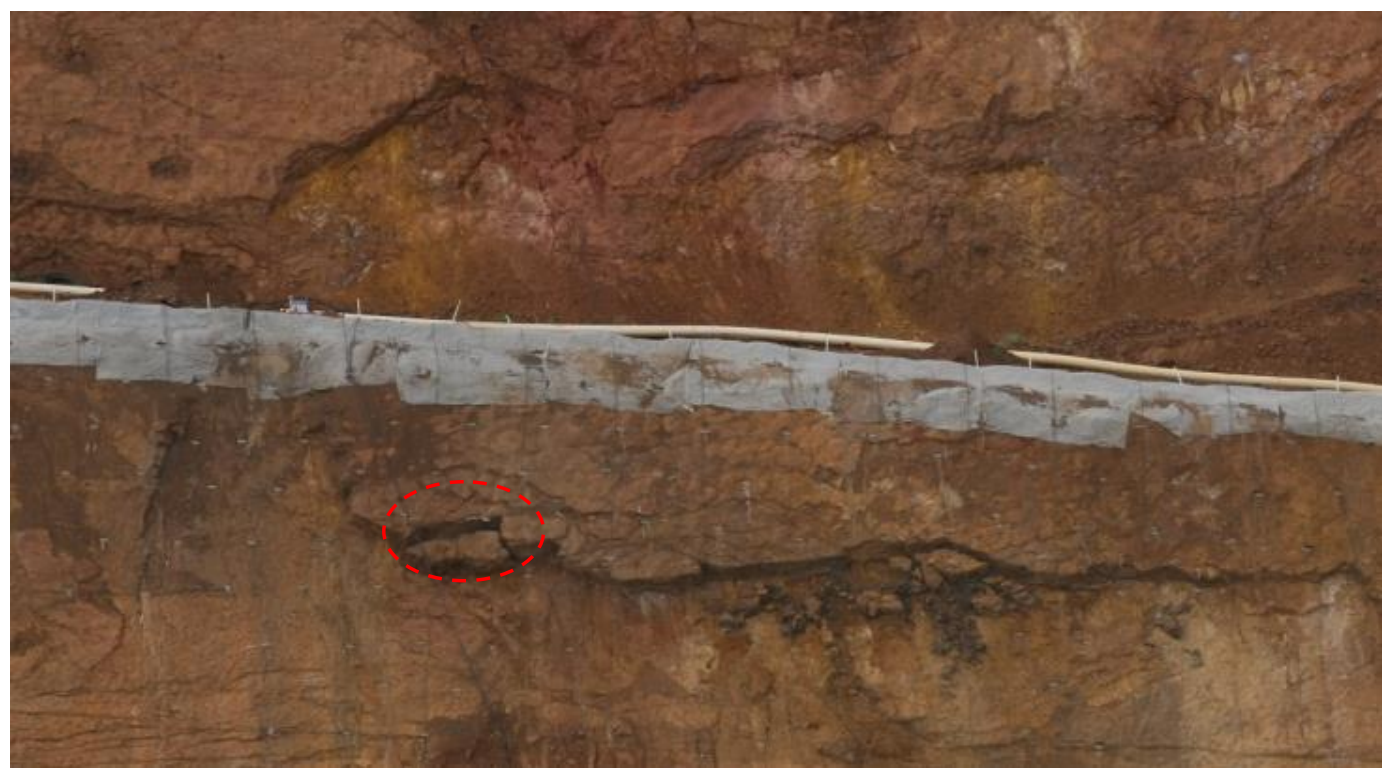

\section{Figure 9 Location of loosened boulders retained by the TECCO mesh system}

The largest bolder, circled in Figure 9 , is approximately $3.5 \mathrm{~m}$ long $\times 0.75 \mathrm{~m}$ thick $\times 1.5 \mathrm{~m}$ width and weighs approximately 12 tonnes. The TECCO system carried out its function successfully by stopping the boulder and retaining it within the mesh without damaging any part of the system.

So checking the slope-parallel force:

- Slope inclination $=40^{\circ}$.

- Specific weight of rock $=30 \mathrm{kN} / \mathrm{m}^{3}$.

- Layer thickness $=0.75 \mathrm{~m}$.

- For every $\mathrm{m}^{2}$ of the mesh, the slope parallel force $\left(Z_{d}\right)$ is:

$$
\mathrm{Z}_{\mathrm{d}}=30 * 0.75 * \sin \left(40^{\circ}\right)=14.6 \mathrm{kN}
$$

The input for $Z_{d}$ in the analysis is $15 \mathrm{kN}$ and the safety factor against release of such a boulder is 1.5 , demonstrating the capacity of the design to satisfy actual slope conditions.

The mesh shearing capacity is proven to be sufficient in the local instabilities between nails. The nail shearing capacity is proven to be sufficient. 


\section{$5 \quad$ Conclusions}

The TECCO system installed at the West Angelas iron ore mine, for rockfall protection purposes, has been physically proven as successful. The design of the system was carried out using the concept of surficial stability to assess the safety factors of the system. The ease in installation of the system allowed the construction process to be carried out without significant technical issues which minimises any possible delays and ultimately makes it a cost and time saving solution. The success of high tensile mesh system proposes an evolutionary rockfall mitigation option to the mining industry. The system was not intended to eliminate completely rockfall hazards but to provide a cost-effective control over the time period when mining operations were to be undertaken in the rockfall trajectory zone.

\section{Acknowledgement}

Geovert acknowledges Rio Tinto for allowing the use of project information and data included in this paper. Geovert also acknowledges Geobrugg for technical support in RUVOLUM concept and the quality information on the TECCO system presented in this paper.

\section{References}

CEN/TC 250 (1997) Eurocode 7 Calcul Geotechnique, viewed 19 August 2013, http://www.danskgeotekniskforening.dk /media/Section_8_EN_1997-1.pdf.

Geobrugg (2010) TECCO Slope Stabilisation System Summary of Published Technical Papers 1998-2009, Dimensioning and application of the flexible slope stabilisation system TECCO made from high-tensile wire mesh in combination with nailing and anchoring in soil and rock.

Geobrugg (2013) RUVOLUM, http://www.geobrugg.com/contento/en-us/Home/Slopestabilization/tabid/2061/Default.aspx.

Joass, G.D. (2013) Risk management and remediation of the north wall slip, West Angelas Mine, Western Australia, in Proceedings International Symposium on Slope Stability in Open Pit Mining and Civil Engineering (Slope Stability 2013), P.M. Dight (ed), 25-27 September 2013, Brisbane, Australia, Australian Centre for Geomechanics, Perth, pp. 995-1010.

Tom Armour, P.P. (2000) Micropile Design and Construction Guidelines. Federal Highway Administration - US Department of Transportation. 